\title{
Optimal Decisions of Sharing Rate and Ticket Price of Different Transportation Modes in Inter-city Transportation Corridor
}

\author{
Zhaoping Tang ${ }^{1,2}$, Jin Qin ${ }^{1 *}$, Huan $\mathrm{Liu}^{2}$, Xiang $\mathrm{Du}^{2}$, Jianping Sun ${ }^{1,2}$ \\ ${ }^{1}$ Central South University, Changsha, ${ }^{2}$ East China Jiao Tong University, Nanchang (China) \\ tzp@erjitu.jx.cn, *Corresponding author:156280412@qq.com,715769813@qq.com,408365288@qq.com,sumjianping@ecitu.jx.cn
}

Received: September 2015

Accepted: November 2015

\section{Abstract:}

Purpose: The paper concerns competition of different transportation modes coexist in intercity transportation corridor. The purpose of this paper is to express the competitive relationship by building mathematical model and obtain the best sharing rate and the optimal ticket price of different transportation modes.

Design/methodology/approach: Firstly, analyzing influencing factors of passenger choice about transportation modes, we designed a utility function of transportation modes. Secondly, referring to the game theory and logit modle, a non-cooperative game model between railway and highway was built. Finally, the model was applied to Nanchang-Jiujiang transportation corridor in China for an empirical analysis.

Findings: The results indicate that the proposed non-cooperative game model is rational and reliable, and it supplies a scientific method to determine the optimal ticket price and passenger sharing rate of different transportation modes, and can be applied to the competition study on different transportation modes in inter-city transportation corridor.

Originality/value: The main contribution of this paper is to built the non-cooperative game model, which can consider the needs of different travelers, and achieve reasonable passenger divergence of different transportation modes and coordinated development of whole transport market.

Keywords: transportation corridor, game model, sharing rate, ticket price 


\section{Introduction}

Transportation corridor is a kind of transportation belt, composed of multiple parallel transport lines of various transportation modes, and connected to a series of economic points, production points and important cities. As the main transportation modes of passengers travel from one city to another in urban agglomeration, transportation corridor has the relatively stable customers and active consumer demand. It has been the main source of profits and becomes the business focus of passenger transport business operators ( $\mathrm{Wu}, 2011)$. With the stable improvement of people's consumption level, people has higher requirement to the service level of travel mode. Except for arriving at destination safely, the other demands, such as economy, quickness, convenience and comfort, is also higher and higher gradually. How to gain market share in greatest degree, so as to obtain the maximum benefit in the market, is the focus of passenger transport operators.

There are mainly four kinds of transportation mode, railway, highway, aviation, and waterways, adopted by passengers when they travel (Roman, Espino \& Martin, 2007). Railway and highway is leading modes of passenger transportation in inter-city transportation corridor with the distance of one or two hundred kilometers. Especially in recent years, with overall construction and rapid ascension of operation level of passenger railway line in China, competition between highway and railway is becoming more intense. However, due to their own characteristics, the two transportation modes cannot replace each other. Therefore, in order to share the passenger volume reasonably, improve the transportation capacity, and provide better services for passengers, the reasonable structure of passenger transportation should be studied.

Aiming at the various transportation modes in the transportation market, experts at home and abroad have conducted in-depth research on passenger sharing results and benefit influence when making competitive strategies. For example, Sato analyzed travel choices of passengers by using multinomial logit model, then got an optimal pricing method. Furthermore, a dynamic pricing model with revenue management as the goal was given, in the model, passengers are setting to choose from various transportation modes, and schedules of transportation modes are setting to change dynamically (Sato \& Katsushige, 2012). Chang proposed a model based on the time value, which is used to calculate the passenger sharing rate of high-speed railway in the market competition. In this model, the author holds that high-speed railway, aviation, traditional railway and highway constitute a time space network in a comprehensive transportation corridor, they compete with each other, finally reach the equilibrium (Chang \& Chang, 2004). In the perspective of microeconomics, Adler constructed a two-stage Nash game model, which can be used to calculate the optimal equilibrium (Aldler, 2001).

In domestic, He chose five factors of price, speed, convenience, safety and comfort, used logit model to analyze sharing rate of each mode transportation in the passenger transportation corridor, besides, combined with the five factors, generalized payoff function was established, 
and maximum likelihood method was adopted, then the numerical value of each parameter was ascertained. Finally, the accuracy of the model was verified by the competition instance of transportation modes between Beijing and Taiyuan (He et al, 2006). With technical feature and economic characteristics of transportation modes in the transportation corridor as a starting point, Beijing to Shanghai as the representative of medium distance of transportation highspeed railway, Dai drew a conclusion that when the price of high-speed railway position in 0.4 yuan/km, it has a strong competitiveness. Moreover, starting from factors that affecting passenger travel, the article established logit sharing model, firstly calculated passenger sharing rate only considering highway and civil aviation, then established sharing model after high-speedway joins in. Eventually, the impact of high-speed railway to the civil aviation and highway transportation is proved (Dai, 2009).

In the research field of pricing strategy modle and algorithm about co-opetition relationship of transportation modes, based on the co-opetition relationship between high-speed railway and traditional railway from Taipei to Kaohsiung, Chiung proposed a model called cyclic coordinate ascent method, and got the MRT pricing strategy from Taipei to Kaohsiung (Chiung, Lee \& Liao, 2010). Considering the constraints of capacity resource and the minimization of travelers' generalized cost, Yang proposed bi-level planning model of market share, and designed heuristic algorithm to solve the model (Yang \& Bell, 1997). Lo utilized three-tier Nested Logit model to analyze selection process of multimode public transportation network, in addition, considering passengers' transfer behaviors and nonlinear cost structure, the model was used to analyze competitive revenue status of different enterprises (Lo, Yip \& Wan, 2014).

In domestic, in order to make reasonable passenger ticket price of railway, Fan built a bi-level planning model. The lower planning is on the basis of wardrop equilibrium principle, which can ensure passengers choose the transportation mode with the minimum generalized travel cost, while the upper planning makes the maximum economic benefits of passenger department as the goal. Afterward, difference method was adopted to solve the model, it provides a basis for establishing reasonable passenger ticket price after the speed-up of railway (Fan \& Zhu, 2004). By analyzing the balance between supply and demand of the transportation market, Si established multi-mode equilibrium assignment model between cities, used sensitivity analysis method to solve equilibrium assignment problem of multi-mode transportation networks, then illustrated the relationship between passenger volume and passenger ticket price of different transportation modes, and analyzed the impact generated by change of passenger volume on revenue of railway (Si \& Gao, 2013). Based on the analysis of competitive environment in medium and long distance passenger market, Ma made a reasonable division between existing passenger railway lines and high speed passenger railway lines. Taking the minimum generalized cost and maximum profit as the goal, multiple nested bi-level planning model was established, moreover, the rationality of the genetic algorithm in solving multi-level planning problems was discussed ( $\mathrm{Ma} \& \mathrm{Li}, 2006$ ). In the perspective of realistic transportation environment, referring to the actual survey data of passengers' travel, taking the factors of 
transportation supplies, passenger demand and market environment as start point, Guo established a game model of high iron and civil aviation with the objective of maximizing social profits, and derived Bayesian Nash equilibrium solution (Guo, 2010). Using the game theory in economics, Zhang built passenger game competition model of different transportation modes in the transportation corridor, afterward, based on the equilibrium solution, made corresponding analysis on the superiority or inferiority of passenger transportation corridor (Zhang \& Zhao, 2012).

On the basis of existing research results, this paper makes a comprehensive consideration about the supply difference factor of transportation modes, the influence factor of passenger travel, and the external market environment factor of passenger transportation, then analyzes dynamic game relationship between operators of different transportation modes, as well as between operators and passengers, furthermore, aiming at various transportation modes in the passenger transportation corridor, studies the influence of different price strategies made by different operators on final passenger sharing rate. Taking Nangchang-Jiujiang corridor for example, non-cooperative Stackelberg double-deck game model on competition strategy choice is build. Thus, game balance point can be determined to achieve the overall optimization of passenger transportation structure and maximize the benefits. In addition, this paper can provide a basis for different transportation enterprises to improve service level and competitive ability and the government to control transportation structure in macroscopic scale.

\section{Analysis of Passenger Travel Mode Influence Factors}

Passengers should choose a transportation mode or a combination of several kinds of mode before they travel, so as to help them complete travel (Martin et al., 2014). They would consider their properties, then calculate cost about traveling by different transportation modes, finally they can choose the transportation mode with the minimum cost and access to maximize the benefit. Therefore, demand factors reflect on the weights determined by passengers of various types when they choose transportation modes in terms of products supply difference (Uchida \& Sugiki, 2013). 


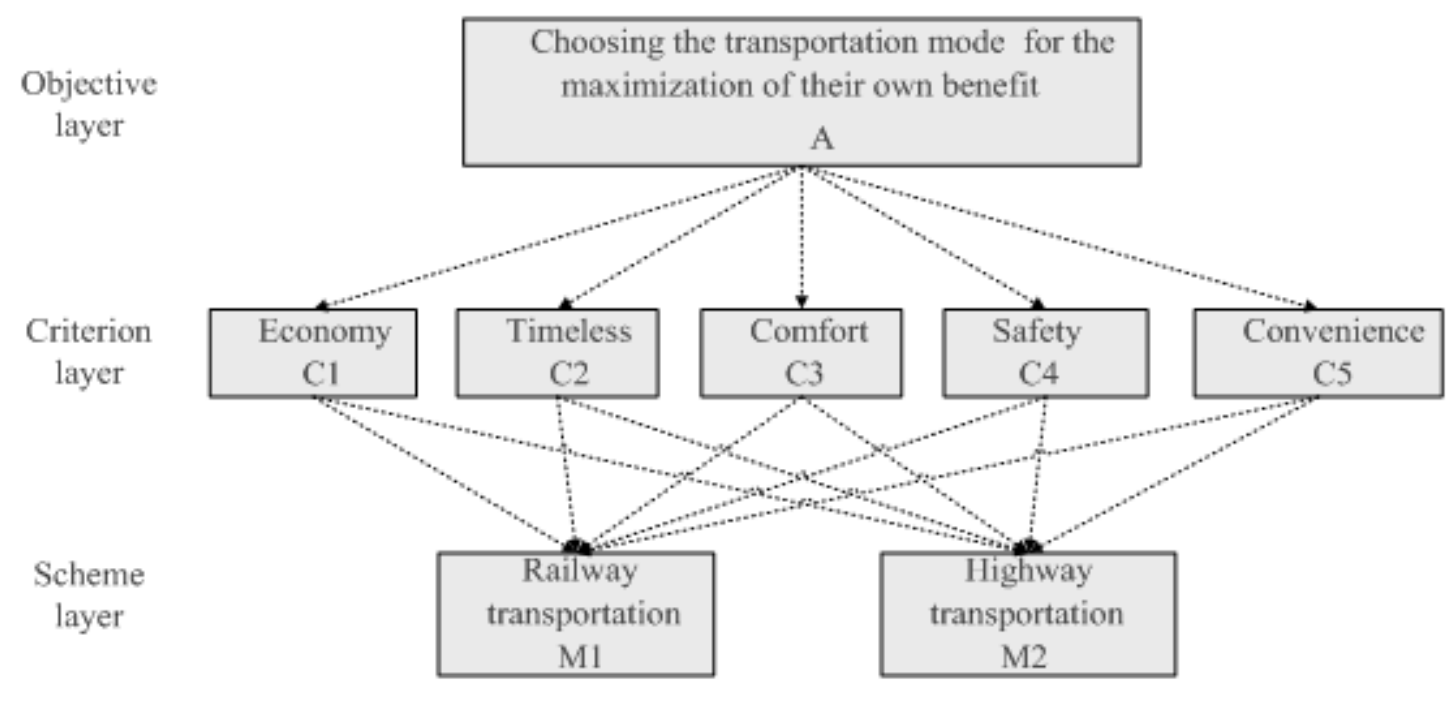

Figure 1 Hierarchical structure of passenger travel influence factors

Figure 1. Hierarchical structure of passenger travel influence factors

Factors of supply difference embodied by features of transportation modes, is essentially the regulatory mastered by operators. With the purpose of adapting to the change of market demand better and faster, operators commonly take measures by adjusting the resources most easy to change (Zhou, 2012). With expert analysis, assuming passengers choose the transportation mode which can bring them biggest benefit. Taking it as the goal, using analytic hierarchy process, this paper establishes hierarchical structure model including objective layer, criterion layer and scheme layer. Factors of supply difference will be simplified to five factors, which are economy, timeliness, comfort, safety and convenience (Figure 1). Economy mainly refers to the cost of the ticket in the corridor. Timeliness mainly refers to the length of travel time, including traveling time and waiting time. Comfort mainly includes the passenger room size, service quality, and space environment. Safety mainly refers to passenger's personal safety and luggage safety. Convenience includes the convenience of booking tickets, transferring and waiting.

\section{Establishment of Non-Cooperative Game Model}

\subsection{Determination of Game Players}

In the light of the characteristics of transportation modes in inter-city transportation corridor (Zhou \& Huang, 2013), inter-city high-speed railway and expressway are ascertained to be the game players. 


\subsection{Analysis of Game Strategy Sets}

According to the main factors that influence passengers' choices of travel modes in section 2, business operators of passenger transportation can take corresponding strategies (Zhao, 2012):

- Economy strategy, means adjusting the price of tickets;

- Timeliness strategy, includes changing stops and routes, and adjusting vehicles' speed and transport organization plan;

- Comfort strategy, includes transferring, renovating and updating stations, raising the service level of crews;

- Safety strategy, includes arranging safety education for employees, adjusting safety facilities of vehicles or station, adjust ing the number of security personnel;

- Convenience strategy, includes adjusting the number of the ticket window, adjusting the number of bus connection lines, adjusting station equipment and refitting vehicle.

\subsection{Establishment of the Model}

- Construction of sharing rate model with double-deck goals

The nether goal:

$$
Y_{i k}=X_{i 1} E_{k}+X_{i 2} T_{k}+X_{i 3} C_{k}+X_{i 4} S_{k}+X_{i 5} B_{k}
$$

In the formula, $Y_{i k}$ represents utility value of the $i$ transportation mode for the kind of passengers. $E_{k}, T_{k}, C_{k}, S_{k}, B_{k}$ represent eigen value of economy, timeliness, comfort, safety and convenience of the $k$ transportation mode. $X_{i n}(n=1,2,3,4,5)$ represent weight value of economy, timeliness, comfort, safety and convenience for the $i(n=1,2,3,4)$ kind of passengers.

Supposing $E$ is the game variable. According to the difference of value about $E$, the biggest utility value should be selected as the optimal decision of passengers. At the same time, we achieved the optimal solution for passengers as the gamer in the nether model.

- The upper goal: firstly calculating passenger volume and share rate. Based on the utility value of transportation modes, which has been calculated in the nether model, the model of logit can be used to calculating passenger capacity and sharing rate.

$$
Q_{k}=\sum_{i} Q_{i k}, Q_{i k}=Q_{k} \cdot P_{i k}, P_{i k}=\frac{e^{\theta Y_{i k}}}{e^{\theta Y_{i d}}+e^{\theta Y_{i b}}}
$$

In the formula, $k$ represents the $k$ transportation mode, $\theta$ represents eigen coefficient, $Q_{k}$ and $P_{k}$ represent passenger volume and sharing rate of the $k$ transportation mode 
respectively, $d$ represents inter-city high-speed railway, $b$ represents expressway, $Q_{i k}$ represents passenger volume of the $k$ transportation mode for the $i$ kind of passengers.

Calculating Earnings: earnings of transportation modes is decided by passenger volume and ticket price. Because the paper studies the passenger transportation sharing rate under the existing traffic facilities, we assume that passenger volume does not change over the time. Earnings of transportation mode is as follows,

$$
R_{d}=Q_{d} C_{d}, R_{b}=Q_{b} C_{b}, Q_{r}=Q_{b} Q_{d}
$$

In the formula, $R$ represents earnings, $C_{b}$ and $C_{d}$ represents ticket price of expressway and intercity high-speed Railway.

- Optimal decision analysis of each stage

Because of the ticket price of Railway is stable, while the ticket price of highway is relatively easy to change, we make such a hypothesis: firstly inter-city high-speed railway makes its ticket price, then expressway decides its ticket price in terms of intercity high-speed railway. Analyze as follows by the converse illation method:

The second stage is the choice of expressway. It makes decisions in view of $C_{d}^{0}$, the ticket price of inter-city high-speed railway, make its price of $C_{b}^{*}$, which is the optimal ticket price for expressway under the price of $C_{d}^{0}$. That can be recorded as $C_{b}^{*} / C_{d}^{0}$, and at the same time, earnings of expressway can be recoded as $R_{b}\left(C_{b}^{*} / C_{d}^{0}\right)$.

Return to analysis of the first stage. By reason of inter-city high-speed railway knows the decision-making method of expressway, which makes the ticket price of $C_{b}^{*}$ and obtain maximum income of $R_{b}$. In order to achieve the best earnings of $R_{d}\left(C_{b}^{*} / C_{d}^{*}\right)$, intercity high-speed railway should select the optimal ticket price of $C_{d}^{*}$. According to the above steps, two inequalities can be drawn as follows:

$$
\begin{aligned}
& R_{d}\left(C_{b}^{*} / C_{d}^{*}\right)>R_{d}\left(C_{b}^{*} / C_{d}\right) \\
& R_{d}\left(C_{b}^{*} / C_{d}^{*}\right)>R_{d}\left(C_{b} / C_{d}^{*}\right)
\end{aligned}
$$

When the two inequality were established at the same time, $C_{b}^{*} / C_{d}^{*}$ must be the equilibrium solutions of this game, which is so-called Nash equilibrium. Both sides of the game will get maximum satisfaction at the moment.

- Establishment of bi-matrix game model

Based on the expression of competitive situation in game theory, bi-matrix game model is established:

$$
G=<(b, d),\left(X_{b}, X_{d}\right),\left(R_{b}, R_{d}\right)>
$$

In the formule, $\mathrm{X}_{b}$ and $\mathrm{X}_{d}$ stand for strategy sets of inter-city high-speed railway and expressway respectively. $R_{b}$ and $R_{d}$ represent earnings of both transportation modes. 
- Set conditions of the optimal solutions

The optimal solutions may be set as the following.

- Satisfaction on ticket price of both sides can reach maximum value, satisfaction of inter-city high-speed railway must be 1 , and expressway reach maximum value.

- Ticket price of both sides can maximize the whole profit including transportation modes and passengers.

Satisfaction refers to another mode obtains satisfaction degree of profit, while fixing the price of one mode. Definition shows as formule (7):

$$
V_{k}^{j}\left(\mathrm{C}_{-k}^{j}\right)=\frac{R_{k}\left(\mathrm{C}_{k}^{j}, \mathrm{C}_{-k}^{j}\right)}{\max _{i=1,2, \ldots, m}\left(R_{k}\left(\mathrm{C}_{k}^{j}, \mathrm{C}_{-k}^{j}\right)\right)}
$$

In the formula, $\mathrm{k}$ values for $\mathrm{b}$ and $\mathrm{d}$, while $-\mathrm{k}$ on behalf of the opponent of $\mathrm{k} . \mathrm{V}_{k}^{j}\left(\mathrm{C}_{-k}^{j}\right)$ represents satisfaction degree of $\mathrm{k}$ with the price of $\mathrm{C}_{k}^{i}$, when the opponent make price strategy of $C_{-k}^{i}$. If it achieves the optimal solution, we can get the formule (8):

$$
V_{b}\left(C_{b}^{*} / C_{d}^{*}\right)+v_{d}\left(C_{b}^{*} / C_{d}^{*}\right)=\max _{\substack{i=1,2, \ldots, m \\ j=1,2, \ldots, n}}\left(V_{b}\left(C_{b}^{i} / C_{d}^{j}\right)+V_{d}\left(C_{b}^{i} / C_{d}^{j}\right)\right)
$$

In addition, $R_{b}\left(C_{b}^{*} / C_{d}^{*}\right)+R_{d}\left(C_{b}^{*} / C_{d}^{*}\right)$ reach the maximum, which is the optimal solution of modle. Then we can calculate the optimal share rate of both transportation modes, $r_{b}$ and $r_{d}$, under the current resources, $r_{b}$ and $r_{d}$ represent the proportion of passengers about expressway and inter-city high-speed railway when they travel.

$$
\mathrm{r}_{b}=Q_{b}^{*} / Q, \mathrm{r}_{d}=Q_{d}^{*} / Q
$$

In the formule, $Q_{b}^{*}, Q_{d}^{*}$ represent passenger volume of expressway and inter-city highspeed railway under the condition of optimal solution.

\section{Empirical Analysis}

Nanchang-Jiujiang transportation corridor is make up of multiple parallel transport lines (including the various transportation facilities, such as terminal, and so on) of various transportation modes, connecting cities of Nanchang and Jiujiang.The major lines are BeijingKowloon Railwayway, Nanchang-Jiujiang Inter-city High-speed Railway, Nanchang-Jiujiang Expressway, 105 National Rd, 316 National Rd, Ganjiang waterway. This paper mainly studies on competitive game between Nanchang-Jiujiang Inter-city High-speed Railway and NanchangJiujiang Expressway. 


\subsection{Passenger Flow Analysis of Transport Corridor}

It will comparatively reflect individual requirements for transport demand direct ly and effectively by structure of economic level. Refer to Nanchang statistic yearbook of 2013 (Statistics Bureau of Jiangxi Provincial, 2013), passenger flow can be divided into four classes. And then questionnaire should be designed to survey on economic structure of passengers in Nanchang-Jiujiang transport corridor. Shows in Table 1.

\begin{tabular}{|l|r|r|}
\hline \multicolumn{1}{|c|}{$\begin{array}{c}\text { Classification of } \\
\text { passenger flow }\end{array}$} & $\begin{array}{c}\text { Resident income } \\
\text { (yuan/month) }\end{array}$ & \multicolumn{1}{c|}{ Proportion } \\
\hline Low income & $<1,300$ & $19.46 \%$ \\
\hline Middle income & $1,300 \sim 3,500$ & $37.21 \%$ \\
\hline Higher income & $3,500 \sim 5,500$ & $31.25 \%$ \\
\hline High income & $>5,500$ & $12.08 \%$ \\
\hline
\end{tabular}

Table 1. Economic structure of passengers in Nanchang-Jiujiang transport corridor

\subsection{Calculating Eigenvalues of Transportation Modes}

Property difference of two kinds of transportation modes can be reflected by the influence factors of passengers when they travel, which are the five factors, economy, timeliness, comfort, safety and convenience. In order to quantify the above factors, ticket price, travel time, operational stability, accident rate and transfer promptness are adopted to represent the factors respectively. Through the contrastive analysis and normalization processing, we can get eigenvalues of inter-city high-speed railway and expressway.

\begin{tabular}{|l|r|r|r|r|r|}
\multicolumn{1}{|c|}{ Transportation mode } & \multicolumn{1}{c|}{$\begin{array}{c}\text { Ticket } \\
\text { price }\end{array}$} & \multicolumn{1}{c|}{$\begin{array}{c}\text { Travel } \\
\text { time }\end{array}$} & $\begin{array}{c}\text { Operational } \\
\text { stability }\end{array}$ & $\begin{array}{c}\text { Accident } \\
\text { rate }\end{array}$ & \multicolumn{1}{c|}{$\begin{array}{c}\text { Transfer } \\
\text { promptness }\end{array}$} \\
\hline $\begin{array}{l}\text { Nanchang-Jiujiang Inter-city } \\
\text { High-speed Railway }\end{array}$ & 0.48 & 0.56 & 0.72 & 0.67 & 0.35 \\
\hline Nanchang-Jiujiang Expressway & 0.52 & 0.44 & 0.28 & 0.33 & 0.65 \\
\hline
\end{tabular}

Table 2. Eigenvalues of the two kinds of transportation modes in Nanchang-Jiujiang

transportation corridor

\subsection{Calculation of Influence Factors' Weights}

On the basis of classification of passengers in section 4.2., we designed questionnaire of passenger preference to influence factors when they travel. One thousand questionnaires were issued at Nanchang Railwayway Station, Nanchang West Railwayway Station, Jiujiang Railwayway Station, and in colleges, enterprises, institutions in the two cities. Finally get 987 effective questionnaires. After systemizing questionnaires and data analysis, we figured up weight vectors of influence factors for four kinds of passengers based on economic structure by hierarchical analysis software of yaahp. The weight vector is reprensented by $W$.

$$
\begin{array}{ll}
W_{1}=(0.32,0.21,0.16,0.14,0.17)^{T} & W_{2}=(0.27,0.23,0.17,0.15,0.18)^{T} \\
W_{3}=(0.22,0.27,0.19,0.17,0.15)^{T} & W_{4}=(0.16,0.30,0.22,0.14,0.18)^{T}
\end{array}
$$




\subsection{Solution Process of the Game Model}

On the basis of survey data, eigen coefficient is achieved to 12.7 by fitting. The total passenger flow is noted for 1 in Nanchang-Jiujiang transportation corridor. According to formulas of (1) and (2), the present share rate of Nanchang-Jiujiang Inter-city High-speed Railway is 72.45 percent, while Nanchang-Jiujiang Expressway is 27.55 percent. In order to obtain the optimal sharing rate and make the best pricing strategy, the modle in chapter 3 should be caculated as follows:

- According to the respective characteristics and restriction conditions(such as policy and cost) of the two transportation modes, combined with the analysis of strategy sets in section 3.2., the ticket price fluctuation range of Nanchang-Jiujiang Inter-city Highspeed Railway can be setted by 20 percent, and Nanchang-Jiujiang Expressway 10 percent.

- On the basis of formula (2), the sharing rates of $P_{b}\left(C_{b}^{i} / C_{d}^{j}\right)$ and $P_{d}\left(C_{b}^{i} / C_{d}^{j}\right)$ can be acquired as shown in Table 3 and Table 4. In accordance with the corresponding ticket price of $R_{b}\left(C_{b}^{i} / C_{d}^{j}\right)$ and $R_{d}\left(C_{b}^{i} / C_{d}^{j}\right)$, under sharing rates, pay-off matrixes of $\mathrm{A}_{b}$ and $\mathrm{A}_{d}$ can be calculated and gotten. Shows in Table 5 and Table 6.

\begin{tabular}{|r|c|c|c|c|c|c|c|c|c|}
\hline $\begin{array}{c}\text { Inter-city } \\
\text { high-speed } \\
\text { railway }\end{array}$ & $\mathbf{3 1 . 5}$ & $\mathbf{3 3 . 5}$ & $\mathbf{3 5 . 5}$ & $\mathbf{3 7 . 5}$ & $\mathbf{3 9 . 5}$ & $\mathbf{4 1 . 5}$ & $\mathbf{4 3 . 5}$ & $\mathbf{4 5 . 5}$ & $\mathbf{4 7 . 5}$ \\
\hline 34 & 0.7605 & 0.7431 & 0.7274 & 0.7025 & 0.6837 & 0.6654 & 0.6420 & 0.6197 & 0.5976 \\
\hline 35.5 & 0.7822 & 0.7652 & 0.7462 & 0.7232 & 0.7028 & 0.6873 & 0.6638 & 0.6372 & 0.6181 \\
\hline 37 & 0.8078 & 0.7844 & 0.7633 & 0.7427 & 0.7245 & 0.7062 & 0.6829 & 0.6614 & 0.6342 \\
\hline 38.5 & 0.8264 & 0.8097 & 0.7863 & 0.7640 & 0.7419 & 0.7265 & 0.7055 & 0.6825 & 0.6574 \\
\hline 41 & 0.8513 & 0.8232 & 0.8027 & 0.7838 & 0.7614 & 0.7403 & 0.7242 & 0.7068 & 0.6712 \\
\hline
\end{tabular}

Table 3. Sharing rate of Nanchang-Jiujiang Inter-city High-speed Railway

\begin{tabular}{|r|l|l|l|l|l|l|r|r|l|}
\hline Expressway & $\mathbf{3 1 . 5}$ & $\mathbf{3 3 . 5}$ & $\mathbf{3 5 . 5}$ & $\mathbf{3 7 . 5}$ & $\mathbf{3 9 . 5}$ & $\mathbf{4 1 . 5}$ & $\mathbf{4 3 . 5}$ & $\mathbf{4 5 . 5}$ & $\mathbf{4 7 . 5}$ \\
\hline 34 & 0.2395 & 0.2569 & 0.2726 & 0.2975 & 0.3163 & 0.3346 & 0.358 & 0.3803 & 0.4024 \\
\hline 35.5 & 0.2178 & 0.2348 & 0.2538 & 0.2768 & 0.2972 & 0.3127 & 0.3362 & 0.3628 & 0.3819 \\
\hline 37 & 0.1922 & 0.2156 & 0.2367 & 0.2573 & 0.2755 & 0.2938 & 0.3171 & 0.3386 & 0.3658 \\
\hline 38.5 & 0.1736 & 0.1903 & 0.2137 & 0.236 & 0.2581 & 0.2735 & 0.2945 & 0.3175 & 0.3426 \\
\hline 41 & 0.1487 & 0.1768 & 0.1973 & 0.2162 & 0.2386 & 0.2597 & 0.2758 & 0.2932 & 0.3288 \\
\hline
\end{tabular}

Table 4. Sharing rate of Nanchang-Jiujiang Expressway

\begin{tabular}{|r|l|l|l|l|l|l|l|l|l|}
\hline $\begin{array}{c}\text { Inter-city high- } \\
\text { speed railway }\end{array}$ & $\mathbf{3 1 . 5}$ & $\mathbf{3 3 . 5}$ & $\mathbf{3 5 . 5}$ & $\mathbf{3 7 . 5}$ & $\mathbf{3 9 . 5}$ & $\mathbf{4 1 . 5}$ & $\mathbf{4 3 . 5}$ & $\mathbf{4 5 . 5}$ & $\mathbf{4 7 . 5}$ \\
\hline 34 & 23.96 & 24.89 & 25.82 & 26.34 & 27.01 & 27.61 & 27.93 & 28.20 & 28.39 \\
\hline 35.5 & 24.64 & 25.63 & 26.49 & 27.12 & 27.76 & 28.52 & 28.88 & 28.99 & 29.36 \\
\hline 37 & 25.45 & 26.28 & 27.10 & 27.85 & 28.62 & 29.31 & 29.71 & 30.09 & 30.12 \\
\hline 38.5 & 26.03 & 27.12 & 27.91 & 28.65 & 29.31 & 30.15 & 30.69 & 31.05 & 31.23 \\
\hline 41 & 26.82 & 27.58 & 28.50 & 29.39 & 30.08 & 30.72 & 31.50 & 32.16 & 31.88 \\
\hline
\end{tabular}

Table 5. Operating earnings of Nanchang-Jiujiang Inter-city High-speed Railway 


\begin{tabular}{|c|c|c|c|c|c|c|c|c|c|}
\hline Expressway & 31.5 & 33.5 & 35.5 & 37.5 & 39.5 & 41.5 & 43.5 & 45.5 & 47.5 \\
\hline 34 & 8.14 & 8.73 & 9.27 & 10.12 & 10.75 & 11.38 & 12.17 & 12.93 & 13.68 \\
\hline 35.5 & 7.73 & 8.34 & 9.01 & 9.83 & 10.55 & 11.10 & 11.94 & 12.88 & 13.56 \\
\hline 37 & 7.11 & 7.98 & 8.76 & 9.52 & 10.19 & 10.87 & 11.73 & 12.53 & 13.53 \\
\hline 38.5 & 6.68 & 7.33 & 8.23 & 9.09 & 9.94 & 10.53 & 11.34 & 12.22 & 13.19 \\
\hline 41 & 6.10 & 7.25 & 8.09 & 8.86 & 9.78 & 10.65 & 11.31 & 12.02 & 13.48 \\
\hline
\end{tabular}

Table 6. Operating earnings of Nanchang-Jiujiang Expressway

- Satisfaction degree of both transportation modes, $V_{b}\left(C_{b}^{i} / C_{d}^{j}\right)$ and $V_{d}\left(C_{b}^{i} / C_{d}^{j}\right)$, can be obtained by the formula (7), as shown in Table 7 and Table 8 . Then we can get comprehensive satisfaction matrix of $V$, which is the sum of the satisfaction degree of both transportation modes. Shows in Table 9.

\begin{tabular}{|r|l|l|l|l|l|l|l|l|r|}
\hline Satisfaction & $\mathbf{3 1 . 5}$ & $\mathbf{3 3 . 5}$ & $\mathbf{3 5 . 5}$ & $\mathbf{3 7 . 5}$ & $\mathbf{3 9 . 5}$ & $\mathbf{4 1 . 5}$ & $\mathbf{4 3 . 5}$ & $\mathbf{4 5 . 5}$ & $\mathbf{4 7 . 5}$ \\
\hline 34 & 0.7879 & 0.8324 & 0.8798 & 0.8929 & 0.89015 & 0.9121 & 0.9413 & 0.9635 & 0.9840 \\
\hline 35.5 & 0.8293 & 0.8578 & 0.9012 & 0.9246 & 0.9415 & 0.9597 & 0.9725 & 0.9928 & 1 \\
\hline 37 & 0.8383 & 0.8735 & 0.8992 & 0.9234 & 0.9497 & 0.9670 & 0.9809 & 0.9952 & 1 \\
\hline 38.5 & 0.7932 & 0.8311 & 0.8643 & 0.8964 & 0.9213 & 0.9434 & 0.9279 & 0.9525 & 0.9983 \\
\hline 41 & 0.7718 & 0.8319 & 0.8584 & 0.8839 & 0.9082 & 0.9189 & 0.9344 & 0.9536 & 0.9728 \\
\hline
\end{tabular}

Table 7. Satisfaction of Nanchang-Jiujiang Inter-city High-speed Railway

\begin{tabular}{|c|c|c|c|c|c|c|c|c|c|}
\hline Satisfaction & 31.5 & 33.5 & 35.5 & 37.5 & 39.5 & 41.5 & 43.5 & 45.5 & 47.5 \\
\hline 34 & 0.7953 & 0.8302 & 0.8635 & 0.8968 & 0.92125 & 0.9331 & 0.9328 & 0.93 & 0.9388 \\
\hline 35.5 & & & & & & & & 0.9705 & .9864 \\
\hline 37 & & & & & & & 0.9799 & 0.9964 & \\
\hline 38.5 & & 0.8292 & & & 205 & 428 & 1 & 1 & 0.9763 \\
\hline 41 & 0.7703 & 0.8272 & 0.8556 & 0.8987 & 0.9229 & 0.9383 & 0.9415 & 0.9484 & 0.9546 \\
\hline
\end{tabular}

Table 8. Satisfaction of Nanchang-Jiujiang Expressway

\begin{tabular}{|r|l|l|l|l|l|l|l|l|r|}
\hline Satisfaction & $\mathbf{3 1 . 5}$ & $\mathbf{3 3 . 5}$ & $\mathbf{3 5 . 5}$ & $\mathbf{3 7 . 5}$ & $\mathbf{3 9 . 5}$ & $\mathbf{4 1 . 5}$ & $\mathbf{4 3 . 5}$ & $\mathbf{4 5 . 5}$ & $\mathbf{4 7 . 5}$ \\
\hline 34 & 1.5832 & 1.6626 & 1.7433 & 1.7897 & 1.8114 & 1.8452 & 1.8741 & 1.8935 & 1.9228 \\
\hline 35.5 & 1.6578 & 1.7244 & 1.7819 & 1.8464 & 1.8807 & 1.9163 & 1.9410 & 1.9633 & 1.9864 \\
\hline 37 & 1.6753 & 1.7408 & 1.8024 & 1.8533 & 1.8972 & 1.9329 & 1.9608 & 1.9916 & 2 \\
\hline 38.5 & 1.5877 & 1.6603 & 1.7267 & 1.7906 & 1.8418 & 1.8862 & 1.9279 & 1.9525 & 1.9746 \\
\hline 41 & 1.5421 & 1.6591 & 1.7140 & 1.7826 & 1.8311 & 1.8572 & 1.8759 & 1.9020 & 1.9274 \\
\hline
\end{tabular}

Table 9. Overall satisfaction of Nanchang-Jiujiang Inter-city High-speed Railway and Nanchang-Jiujiang Expressway

- Finding out the maximum of overall satisfaction, which can achieve entirety optimal. The corresponding ticket price of Nanchang-Jiujiang Inter-city High-speed Railway is 47.5 yuan, and Nanchang-Jiujiang Expressway is 37 yuan. At the moment, the decision is the game optimal solution of both transportation modes.

- Passenger volume of both transportation modes can be calculated through game optimal solution. Based on the formula (9), the optimal sharing rate of NanchangJiujiang Inter-city High-speed Railway is 63.42 percent, while Nanchang-Jiujiang Expressway is 36.58 percent under the current resources. 


\subsection{Analysis of Result}

The result is that inter-city high-speed railway should raise its ticket price from 39.5 yuan to 47.5 yuan and expressway should keep the present ticket price of 37 yuan. The sharing rate of railway fell from $72.45 \%$ to $63.42 \%$, while expressway increase from $27.55 \%$ to $36.58 \%$. With the respective earnings of 30.12 and 13.53 , both railway and expressway obtain maximum satisfaction. The sum of satisfaction gets to 2 . At the moment, inter-city high-speed railway and expressway gain maximum benefit, and reach Nash equilibrium of the game.

At the present game of the two transportation modes, Nanchang-Jiujiang Intercity High-Speed Railway takes advantage of economy and timeliness, which are two main factors affecting passenger to make a choice. It obtains passenger flow with a large proportion by the lower ticket price and the faster speed. But for the high transportation cost and large passenger flow, intercity high-speed railway does not get the best earnings and the biggest satisfaction (Yin, 2014; Zhu, 2014). On the contrary, despite of a reasonable pricing, Nanchang-Jiujiang Expressway can't obtain the more passenger flow and the best earnings under the present pricing strategy of its opponent. In the current unreasonable and unstable state, game equilibrium point should be sought for the best strategy of both sides. Under the point, passengers who are more sensitive to ticket price and time may transfer from one transportation mode to another in the corridor. Meanwhile, passengers who are less sensitive to ticket price can prefer the transportation mode they like more expediently and easily. In this way, it can make a reasonable allocation of passenger volume and obtain the optimal sharing rate. Finally it can reach the biggest satisfaction and reach the game equilibrium of both transportation modes.

\section{Conclusions}

It can be seen that the conclusion of non-cooperative game model established in this paper has a good consistent with the actual situation. It is helpful for the improvement of the intercity transportation corridor structure. In addition, it can provide better service quality for passengers based on their various demands. The modle can be applied to game research on two kinds of transportation modes. Based on the game analysis of Nanchang-Jiujiang transportation corridor, some advices can be put forward to the inter-city transportation corridor with short distance as follows:

- From the view of transportation modes' managers, they can adjust the proportion of various transportation modes in transportation corridor by policy intervention, such as control the pricing scope. It finally realizes reasonable divergence of passengers and achieves coordinated development of the whole operation.

- Owing to the relatively low price of inter-city high-speed railway, ticket price should be raised appropriately. So part of the passenger flow can be transfered to expressway and 
other transportation modes. To this, operating costs would be reduced, inter-city highspeed railway may obtain a better earnings and greater satisfaction.

- As the operators of expressway, their competitiveness can be enhanced by improving the way of booking tickets, perfecting service facilities and promoting quality of service. In such ways passengers that more sensitive to price can be attracted to expressway.

\section{Acknowledgments}

This work is supported by Soft Sciences Foundation Project of Jiangxi Province in 2015 (Project name: Research on Sharing Rate and Pricing Strategy of Passenger Transportation in Changjiu Inter-city Transportation Corridor, NO. 20151BBA10049).

\section{References}

Adler, N. (2001). Competition in a deregulated air transportation market. European Journal of Operational Research, 129(2), 339-348. http://dx.doi.org/10.1016/S0377-2217(00)00231-9

Chang, I., \& Chang, G.L. (2004). A Network-based Model for Estimating the Market Share of a New High-speed Rail System. Transportation Planning and Technology, 27(2), 67-90. http://dx.doi.org/10.1080/0308106042000218186

Chiung, W.H., Lee, Y.S., \& Liao, C.H. (2010). Competition between high-speed and conventional rail systems: A game theoretical approach. Expert Systems with Applications, $37(4), 55-63$.

Dai, L.L. (2009). Research on the Competition Relationship between High-speed Railway and Other Transport Ways. BeiJing: Beijing JiaoTong University.

Fan, L.L., \& Zhu, J.G. (2004). Study of Railway Passsenger-ticket Pricing and Velocity Benefit Under the Condition of Market Economy. Technology and Economy in Areas of Communications, (5), 66-69.

Guo, C.J. (2010). Research on the Game Theoretical Model of Passenger Traffic Sharing Between High-Speed Railway and Civil Aviation. BeiJing: Beijing JiaoTong University.

He, Y.Q., Mao, B.H., Chen, T.S., et al. (2006). The Mode Share Model of the High-speed Passenger Railway Line and Its Application. Journal of the China Railway Society, 28(5), $18-21$.

Lo, H., Yip, C.W., \& Wan, Q.H. (2014). Modeling competitive multi-modal transit services: a nested logit approach. Transportation Research Part C Emerging Technologies, 12(3), 251-272. 
Martin, J.C., Roman, C., García-Palomares J.C., et al. (2014). Spatial analysis of the competitiveness of the high-speed train and air transport: The role of access to terminals in the Madrid-Barcelona corridor. Transportation Research Part A, 69(1), 392-408.

Ma, S., \& Li, X. (2006). Method for Pricing of High Speed Passenger Lines in Consideration of Share and Competition in a Railway Transportation Channel. Journal of Southwest Jiaotong University, 41(5), 603-607.

Roman, C., Espino, R., \& Martin, J.C. (2007). Competition of high-speed train with air transport. The case of Madrid-Barcelona, 13(5), 277-284.

Sato, K., \& Katsushige, S. (2012). Dynamic pricing of high-speed rail with transport competition. Journal of Revenue and Pricing Management, 11(5), 548-559. http://dx.doi.org/10.1057/rpm.2011.29

Si, B.F., \& Gao Z.Y. (2013). Modeling Network Flow and System Optimization for Traffic and Transportation System. China Communications Press.

Statistics Bureau of Jiangxi Provincial (2012). Available online at: Http://www.jxstj.gov.cn/resource/nj/2013CD/indexch.htm-Statistical Yearbook of Jiang Xi Province in 2013.

Uchida, K., \& Sugiki, N. (2013). Travel demand estimation risk for high-speed railway transport considering travel price competition. Journal of Advanced Transportation, 47(8), 737-750. http://dx.doi.org/10.1002/atr.194

Wu, W.X. (2011). Research on the share rate of passenger flow and transportation organization strategy in Railwayway transportation corridor. China Railwayway Science, 32(2), 126-130.

Yang, H., \& Bell, M.G.H. (1997). Traffic restraint, road pricing and network equilibrium. Transportation Research B Methodological, 31(4), 303-314. http://dx.doi.org/10.1016/S01912615(96)00030-6

Yin, Y. (2014). Evaluation of Changjiu Inter-city Railwayway Passenger Train Operation Plan. Journal of East Chian Jiaotong University, 31(1), 63-68.

Zhang, J.N., \& Zhao, P. (2012). Research on Market Equilibrium of Regional Passenger Transport Corridors Based on Game Theory. Journal of the China Railway Society, 34(5), $1-8$.

Zhao, Y.G. (2012). Study on Reasonable Division of Inter-City Passenger Transportation Tasks in Regional Corridor. Railway Transport and Economy, 34(4), 67-73.

Zhou, L., \& Huang, Y. (2013). Game analysis on market competition in passenger transportation corridor. Highways\&Automotive Applications, (3), 80-84.

Zhou, Y.Q. (2012). Research on sharing rate of all kinds of modes in transportation corridor based on game theory. Cheng Du: Southwest Jiaotong University. 
Zhu, Y.J. (2014). Research of Passenger Train Operation Scheme for Intercity Passenger Dedicated Line Based on Passenger Flow Dynamic Assignment. Bin Jing: Beijing Jiaotong University.

Journal of Industrial Engineering and Management, 2015 (www.jiem.org)

Article's contents are provided on an Attribution-Non Commercial 3.0 Creative commons license. Readers are allowed to copy, distribute and communicate article's contents, provided the author's and Journal of Industrial Engineering and Management's names are included.

It must not be used for commercial purposes. To see the complete license contents, please visit

http://creativecommons.org/licenses/by-nc/3.0/. 